\title{
How the Conscious and Automatic Information Processing Modes Influence Consumers' Continuance Decision in an e-Commerce Website
}

\author{
Christy M.K. Cheung \\ Department of Finance and Decision Sciences \\ Hong Kong Baptist University, Hong Kong, China \\ ccheung@hkbu.edu.hk \\ Xiabing Zheng* \\ School of Management \\ University of Science and Technology of China, China \\ is.xzheng@gmail.com \\ Matthew K.O. Lee \\ Department of Information Systems \\ City University of Hong Kong, Hong Kong, China \\ ismatlee@cityu.edu.hk
}

\begin{abstract}
Conscious and automatic information processing modes represent two approaches to deal with IS continuance. Existing IS studies mostly viewed them as two independent systems and examined IS continuance through either a cognitive deliberating process or an automatic process. In this study, we attempt to clarify the complex nature of IS continuance by examining various interactions between the two information processes. Particularly, we argued that habit activates the heuristic information processing mode and facilitates consumers' decision making through interacting with key elements of the rational decision process. We conducted a longitudinal study to empirically test the research model with 385 consumers of an e-commerce website. The results show that the two information processing modes work in parallel to explain consumers' continuance decision. Satisfaction, perceived enjoyment, and alternative attractiveness have significant direct effects on continuance intention. Furthermore, habit exhibits a significant negative moderating effect on the relationship between alternative attractiveness and continuance intention. We believe that this study provides new insights to both IS research and practice.
\end{abstract}

Keywords: IS continuance, Human information processing, E-commerce websites, Longitudinal study, Consumers' continuance decision 
How the Conscious and Automatic Information Processing Modes Influence / Cheung et al.

\section{Introduction}

In the past two decades, much IS literature focused primarily on user acceptance and initial use of new technologies. Recently, there has been increasing attention given toward IS continuance (Bhattacherjee, 2001; Burton-Jones and Gallivan, 2007; Hsieh et al., 2008; Jasperson et al., 2005). Consistent with the observations of Ortiz de Guinea and Markus (2009), the foundations of existing IS continuance work was mostly the theoretical tradition of planned behavior and reasoned action, as well as the expectation disconfirmation framework. In other words, IS continuance is fundamentally intentional behavior that is driven by conscious intentions, resulting from a rational decision making process. This line of research extends from the assumption that behavior is driven by deliberative evaluation and reasoning (Conscious Information Processing Mode). However, literature in psychology and social psychology has posited that repetitive behaviors are automatically evoked. When behaviors are repeated in consistent settings, decision makers activate an automatic response and arrive at a choice (Chartrand and Fitzsimons 2011). IS researchers have begun to incorporate the concept of habit in the investigation of IS continuance (Automatic Information Processing Mode). They have made important contributions by raising IS researchers' awareness of the importance of focusing more attention on the ways in which automatic information process might influence IS continuance (Kim et al., 2005; Limayem et al., 2007).

Conscious and automatic information processing modes represent two approaches to deal with IS continuance. Existing IS studies have viewed the conscious and automatic information processes as two independent systems and examined continuing IS use through either a cognitive deliberating process or an automatic process. Though psychologists and social psychologists also adopted this dichotomous view to explain how conscious information process (e.g., intention) and automatic information process (e.g., habit) guide human behavior (Chartrand and Fitzsimons, 2011), they have argued that psychological processes range on a continuum from highly conscious to entirely unconscious, and the two information processing modes interact at various stages of processing. Therefore, it is important to clarify the complex nature of IS continuance by examining various interactions between conscious processing and automatic influences. Particularly, we believe that habit, which represents a major form of automaticity, activates the heuristic information processing mode and facilitates decision making through interacting with key elements of the rational decision process. In addition, prior studies on IS continuance mostly relied on cross-sectional data. Anecdotal evidence has suggested that perceptions, intentions, habits, and behaviors are highly related, but there has been little empirical evidence regarding this issue. Verhoef (2003) also argued that longitudinal data that combine survey measures should be used to establish a causal relationship between perceptions, intentions and behaviors. To fill this void in the IS literature, we examine the operation and interplay of the two processes in shaping consumers' continuance decision in a longitudinal setting.

The paper is divided into the following sections: The next section addresses the theoretical foundations of the research model. The third section presents the research model and hypotheses. The fourth section describes a longitudinal study of consumers of an e-commerce website to empirically test our research model. The fifth section presents the results of our empirical study. Finally, the paper is concluded by discussing the implications for both research and practice. 


\section{Theoretical Foundations}

In recent years, IS researchers have begun to explore the underlying mechanisms explaining IS continuance. Ortiz de Guinea and Markus (2009) described this new direction as "one of the most welcome developments in recent Information Systems Scholarship" (p.433). In this section, we provide a review of the two main streams of literature of IS continuance.

\section{Conscious and Rational Decisions}

A majority of the existing works on IS continuance has been based on the theoretical tradition of planned behavior and reasoned action and examined the continuing of IS use in a longitudinal setting (e.g., Karahanna et al., 1999; Venkatesh and Davis, 2000). Researchers have also used expectation confirmation theory to address how users evaluate IS use and how this evaluation affects satisfaction as well as continuance intention. Bhattacherjee's (2001) IS continuance model Bhattacherjee (2001), based on expectation confirmation theory, is the most well-cited research framework in the study of IS continuance. The model suggests that IS continuance intention is predominantly determined by satisfaction and perceived usefulness. It also relates satisfaction and perceived usefulness to the degree with which user expectation about an IS is confirmed. Expectation provides the baseline level against which confirmation is assessed by users to determine their evaluative response or satisfaction. The better their expectation is met, the more useful it appears to users and the more satisfied they are. This line of research derives from the assumption that human behavior is driven by conscious, deliberative thought and reasoning. IS researchers have applied the IS continuance model to explain continuance behavior in the online environment (Cheung and Lee, 2009; Cheung et al., 2013; Chiu and Wang, 2008).

\section{Automatic and Habitual Responses}

In recent years, IS researchers have begun to incorporate the concept of habit in the investigation of IS continuance (Kim et al., 2005; Limayem et al., 2007). Some researchers hypothesized that intention and habit interact in the prediction of continuing IS use (Limayem et al., 2007), while others examined IS habit as a direct effect on IS use (Kim et al., 2005; Limayem and Hirt, 2003). There are two main streams of research explaining an automatic mental process (Bargh and Chartrand, 1999). The first refers to an intentional goal-directed process that becomes more efficient over time and practice. For example, Aarts et al. (1997) asserted that when behaviors are repeated in consistent settings, habits are automatically evoked and do not need much intentional effort or extensive planning. The second assumes that it takes place without any intention or awareness that it was taking place. For instance, Wood and Neal (2009) suggested that most of our daily activities are habitual responses in memory that are triggered by context cues without depending on goals. Most IS researchers adopt the first stream of research and agree that when individuals are repeatedly performing a particular behavior (e.g., using an IS), the future behavior (e.g., continue to use an IS) will be largely determined by habit rather than reflective and deliberate cognitive thought. The concept of habit has been widely adopted to explain the continuance of an information system, including e-learning platforms (Kim et al., 2005; Limayem and Cheung, 2008; Limayem et al., 2007; Ortiz de Guinea and Markus, 2009). 


\section{Research Model and Hypotheses}

Figure 1 depicts our research model. The IS continuance literature, along with its notions of a conscious/cognitive information processing mode and an automatic information processing mode, offers a theoretical basis for explaining consumers' continuance decision in the current study. Regarding the conscious information process, the continued use is driven by two contrasting forces: dedication and constraint. A customer may analyze the dedication and constraint of using an e-commerce website and, in so doing, deliberately reflect on the beliefs and evaluations. Regarding the automatic process, habit advances the efficient execution of behavior by enhancing the perceptual readiness for relevant cues. Continued use is driven by habit and its interaction with key conscious elements (i.e., perceived enjoyment and attractiveness of alternative) in the decision process. This section provides a theoretical rationale for the two information processes and proposes research hypotheses.

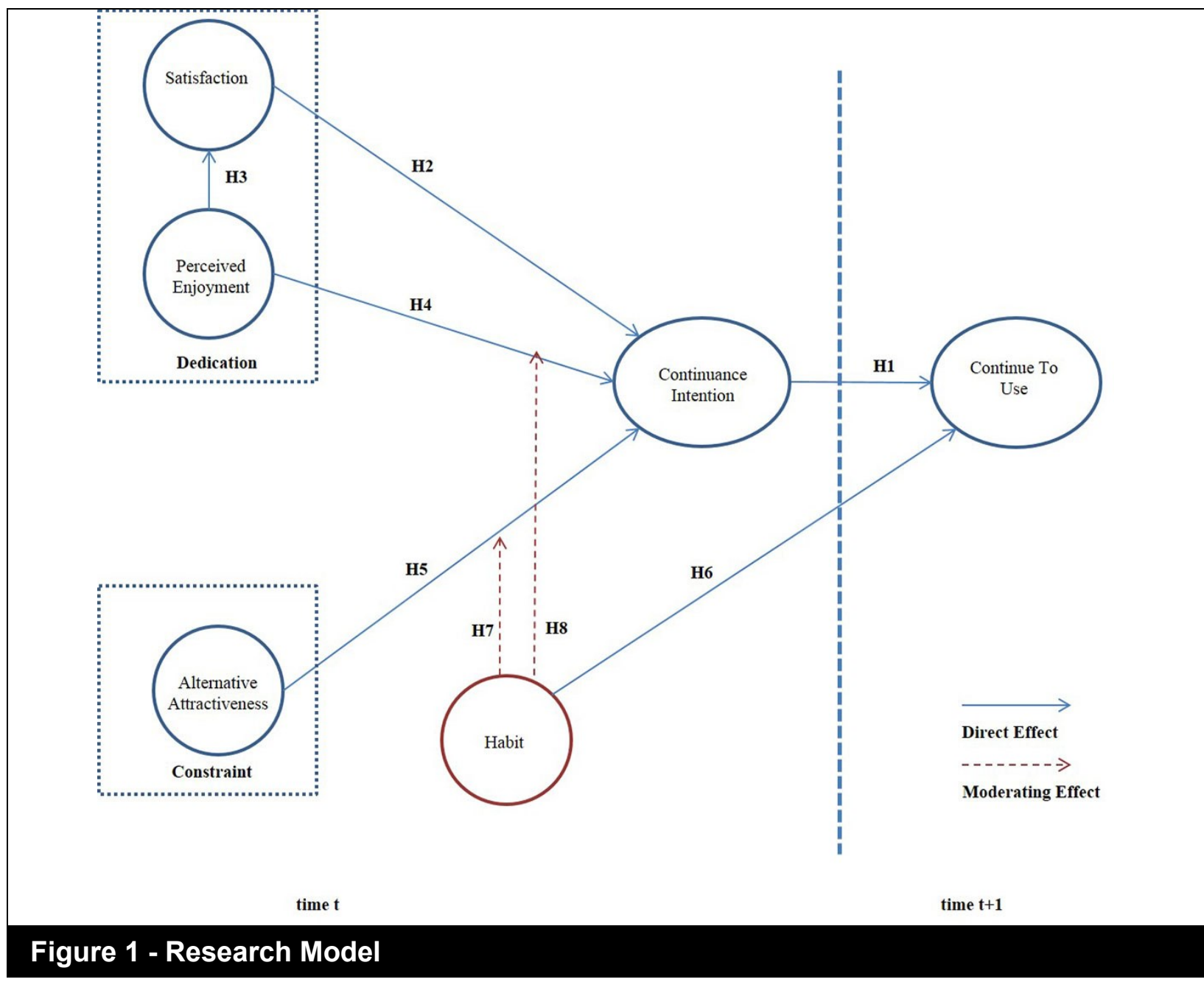




\section{Conscious Process: Continuance Intention}

A majority of existing works on IS continuance maintains theoretical continuity with the IS adoption literature in which IS continuance is fundamentally driven by continuance intention. The positive relationships between continuance intention and behavior, derived from underlying theories from social psychology, have been extensively validated in numerous empirical studies of IS usage (e.g., Bhattacherjee, 2001; Thong et al., 2006). This generalized relationship should also hold true in the current investigation. In other words, when consumers have formed an intention to continue to use an e-commerce website, it is very likely that they will continue to use it in the future.

$\mathrm{H} 1$ : Continuance intention is positively related to continue to use an e-commerce website

\section{Conscious Information Processing Mode: Two Contrasting Forces}

In consumer behavior literature, researchers (Bendapudi and Berry, 1997) argued that the continuance of a relationship is determined by two contrasting forces: dedication and constraint. They believed that consumers choose to continue a relationship because either the service offers value (i.e., perceived benefits) or they feel lock-in (i.e., switching cost). The two contrasting forces are found in play in determining continuance of a relationship (Kim and Son, 2009). According to social exchange theory (Blau, 1964), people consider both benefit and cost factors before they make a rational decision about their actions. Satisfaction and perceived value succinctly representing the dedication of using an information system are two wellstudied factors in IS continuance research (Bhattacherjee, 2001; DeLone and McLean, 2003; Rai et al., 2002).

Satisfaction is an evaluative affect which is based on one's direct, first-hand experiences with using an information system. It refers to an emotional component in the IS continuance stage (Zhang, 2013). Satisfied users are likely to continue to use an IS. Prior IS studies have provided empirical support of the link between satisfaction and continuance intention (Bhattacherjee, 2001). In the current study, we believe that satisfied consumers are more likely to form intention to continue to use an e-commerce website.

$\mathrm{H} 2$ : User satisfaction is positively related to continuance intention to use an ecommerce website

In this study, perceived value refers to the perceived enjoyment of using an information system. Perceived enjoyment is an important user belief that can lead to successful IS usage. Prior studies have empirically confirmed the saliency of this concept in explaining both IS acceptance (Venkatesh and Brown, 2001) and IS continuance (Thong et al., 2006). The concept is particularly important in the case of hedonic information systems. In our current investigation of using an ecommerce website, we believe that perceived enjoyment is a critical determinant explaining continuance intention. Indeed, the role of perceived enjoyment and user satisfaction as well as continuance intention has been empirically validated in prior literature (Kim, 2010; Thong et al., 2006). We expect that these relationships will also be held in the current investigation.

H3: Perceived enjoyment is positively related to user satisfaction with an ecommerce website

H4: Perceived enjoyment is positively related to continuance intention to use an ecommerce website

Alternative attractiveness refers to the extent to which an alternative information system is perceived as being beneficial over (i.e., having more attractive features than) the currently adopted one. The attractiveness of alternatives is often viewed as a major reason that drives consumers to 
How the Conscious and Automatic Information Processing Modes Influence / Cheung et al.

switch services (Keaveney, 1995; Ping Jr, 1993). In the IT switching literature, researchers (Ye and Potter, 2011; Zhang et al., 2009) have empirically shown that a user is more likely to switch to an alternative if he or she expects it to be better than the incumbent. Colgate and Lang (2001) suggested that switching and continuance are two sides of the same coin and are likely influenced by the same factors in opposite directions.

$\mathrm{H}$ 5: Alternative attractiveness is negatively related to continuance intention to use an ecommerce website

\section{Automatic Information Processing Mode: Habit}

IS researchers have begun to incorporate the concept of habit into the studies of IS continuance. Most researchers agree that when individuals are repeatedly performing a particular behavior (e.g., using an IS), the future behavior (e.g., continuing IS use) will be largely determined by habit (Ortiz de Guinea and Markus, 2009). The direct effect of habit has also been empirically examined in prior IS studies (Kim et al., 2005; Limayem and Hirt, 2003). Thus, we also expect that habitual use of an e-commerce website will have a direct effect on the continuance of an e-commerce website.

H6: Habit is positively related to continue to use an e-commerce website

Consumer psychologists asserted that most behaviors and decisions are multiply determined by both conscious and nonconscious processes (Chartrand and Fitzsimons, 2011). Habit, which represents a major form of automaticity, activates the heuristic information processing mode and facilitates decision making through interacting with key elements of the rational decision process. This heuristic process can be conceived of as a kind of cognitive shortcut which frees the newer, revolutionary, and conscious mind for other tasks. According to self-perception theory (Bem, 1972), people observe their own behavior and determine their own attitude.
When habit is strong, people bias their behavior beliefs toward their own habitual behavior. In other words, habit strengthens the impact of the perceived values and the behavior. Thus, we expect that the impact of perceived enjoyment on continuance intention will be larger with people with a strong habitual mind-set of using an ecommerce website.

H7: Habit positively moderates the association between perceived enjoyment and continuance intention

Verplanken and Aarts (1999) argued that strong habits make an individual less attentive to new information. When the habitual mind-set of doing a certain behavior is strong, people adopt relatively simple and heuristic-based choice rules which results in a minimal search for new information and little attention given to alternative courses of action. Gefen (2003) has made a similar argument that habit will interfere with the adoption of new behavior and thus increase the continuance of existing behavior. In this study, we extend from this argument and hypothesize that when the habitual mind-set of using an ecommerce website is strong, the impact of alternative attractiveness on continuance intention will be reduced.

H8: Habit negatively moderates the association between alternative attractiveness and continuance intention

\section{Methodology}

\section{Study Context and Samples}

In the current study, we examined how the two information processing modes interact and shape the complex nature of IS continuance. We used a sample of TaoBao (www.Taobao.com) consumers to examine our conceptual model. TaoBao Marketplace is a leading company in China. People use this e-commerce website to buy and sell products. Our research model was assessed in a longitudinal setting. As shown in Figure 2, data was collected at two different point of time. At time $t$, we collected 
responses related to the factors of the two processing modes, including satisfaction, perceived enjoyment, alternative attractiveness, habit, and continuance intention. At time $t+1$ ( 3 weeks after the first round), participants were asked to complete another set of questionnaire with measures about their continued use.

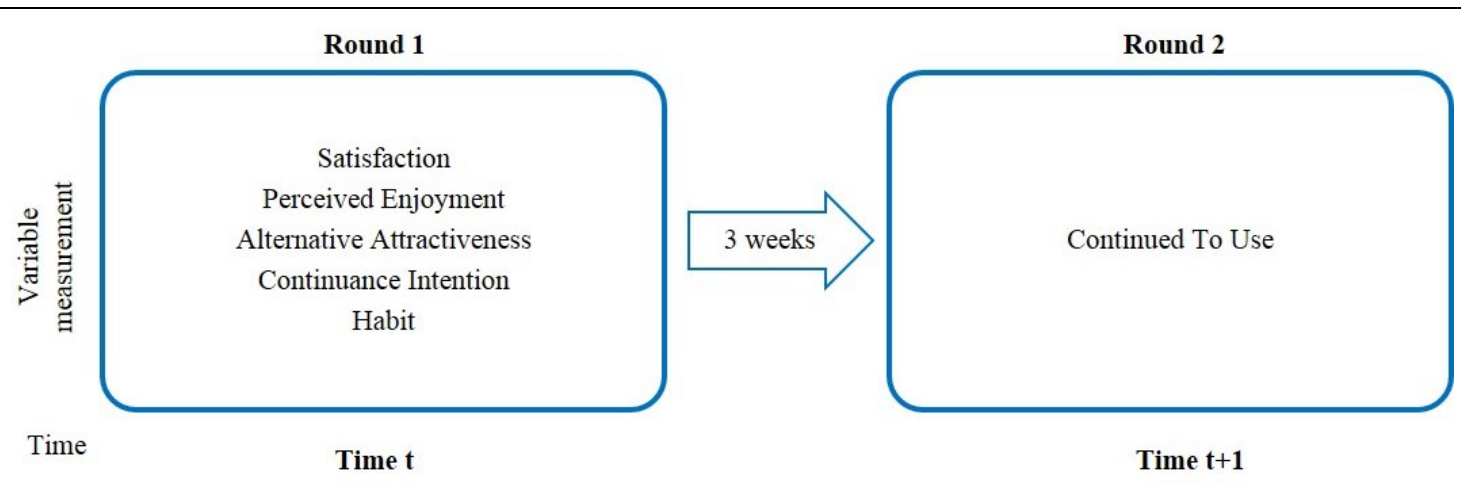

\section{Figure 2 - Data Collection}

In order to improve the response rate and sample quality, we employed a market research firm for data collection. The market research firm provided IP addresses to prevent double- counting of survey respondents. A total of 1356 people accessed the survey link of the first questionnaire. Among them, 850 responded in the first round (time $t$ ). Of the original 850 respondents, 385 completed the questionnaire in the second round (time $t+1)$. Table 1 presents the demographic profiles of respondents. Among the 385 respondents, $55 \%$ was female and $45 \%$ was male. $33.5 \%$ of our respondents aged $18-25$ and $30 \%$ aged $31-40$. A majority of the respondents $(81.3 \%)$ had an education level of university or above.

\section{Table 1 - Demographic profile of the respondents}

\begin{tabular}{|l|c|c|}
\hline Characteristics & Distribution (\%) \\
\hline \multirow{3}{*}{ Gender } & Male & 44.9 \\
\hline \multirow{4}{*}{ Age (year) } & Female & 55.1 \\
\cline { 2 - 3 } & Under 18 & 0.3 \\
\cline { 2 - 3 } & $18-25$ & 33.5 \\
\cline { 2 - 3 } & $26-30$ & 29.4 \\
\cline { 2 - 3 } & $31-40$ & 30.1 \\
\cline { 2 - 3 } & Over 40 & 6.8 \\
\cline { 2 - 3 } & High School & 0.3 \\
\cline { 2 - 3 } & Above High School & 18.4 \\
\cline { 2 - 3 } & Bachelor & 71.2 \\
\hline
\end{tabular}

\section{Common Method Bias}

The longitudinal study was adopted as it has been identified as an effective method to reduce common method bias (Podsakoff et al., 2003) and to draw causal inference (Jing and Xie, 2011). However, as with all self-reported data, common method variance might still be a potential threat (Podsakoff et al., 2003). In the light of this, it is necessary to perform additional statistical analyses. First, we performed a Harman's single-factor test (Podsakoff et al., 2003). The exploratory principal components analysis revealed that the first component explained only $44 \%$ of the variance. Second, we applied the procedure recommended by Pavlou et al. (2007). The correlations between variables in our data 
How the Conscious and Automatic Information Processing Modes Influence / Cheung et al.

ranged from -0.13 to 0.74 (see Table 4 ), indicating that there was no systematic bias in the data. Third, following Liang et al. (2007), we compared the variance explained of the common method bias factor and all other factors of the research model. The results demonstrated that the average variance of substantive factors is 0.864 , whilst the average variance of the method based construct is 0.022 . The ratio of substantive variance to method variance is about 39:1. The common method factor only explained $2 \%$ of the overall covariance, confirming that the common method bias is not a threat to the results of the current study.

\section{Non-response Tests}

ANOVA was used to check for differences in gender, age, education and income between early and late respondents to measure non-response bias (Armstrong and Overton, 1977). Early respondents were those who did not answer the second questionnaire, while late respondents were those answered both questionnaires. According to the comparison, no significant differences existed in gender $(p=.155)$, age $(p=.146)$, education $(p=.866)$, and income $(p=.437)$.

\section{Operationalization of Research Variables}

Table 2 lists the measures used. All our measures have been validated in prior research, and we have modified the wordings so as to fit the context of ecommerce websites (i.e., TaoBao).

\begin{tabular}{|c|c|c|}
\hline Constructs & Measures & Sources \\
\hline SAT & $\begin{array}{l}\text { In your relationship with TaoBao, your overall transaction experience is } \\
\text { 1. Highly unsatisfactory <------>highly satisfactory } \\
\text { 2. Very unpleasant <----> very pleasant } \\
\text { 3. Terrible <----->delightful }\end{array}$ & $\begin{array}{c}\text { (Seiders et al., } \\
\text { 2005) }\end{array}$ \\
\hline PEN & $\begin{array}{l}\text { 1. I have fun interacting with TaoBao. } \\
\text { 2. Using TaoBao provides me with a lot of enjoyment. } \\
\text { 3. I enjoy using TaoBao. }\end{array}$ & $\begin{array}{l}\text { (Agarwal and } \\
\text { Karahanna, } \\
\text { 2000) }\end{array}$ \\
\hline AAT & $\begin{array}{l}\text { 1. There are other online shopping platforms that provide high service quality. } \\
\text { 2. There are online shopping platforms I find more attractive than the one I am } \\
\text { using (TaoBao). } \\
\text { 3. I know that there are alternative online shopping platforms I can switch to } \\
\text { from TaoBao. }\end{array}$ & $\begin{array}{c}\text { (Zhang et al., } \\
2009)\end{array}$ \\
\hline ICU & $\begin{array}{l}\text { 1. My willingness to buy a product again from TaoBao is high. } \\
\text { 2. The probability that I would consider buying a product again from TaoBao is } \\
\text { high. }\end{array}$ & $\begin{array}{c}\text { (Seiders et al., } \\
2005)\end{array}$ \\
\hline $\mathrm{HAB}$ & $\begin{array}{l}\text { 1. Using TaoBao has become automatic to me. } \\
\text { 2. Using TaoBao is natural to me. } \\
\text { 3. When faced with a particular product, using TaoBao is an obvious choice for } \\
\text { me. }\end{array}$ & $\begin{array}{l}\text { (Limayem and } \\
\text { Cheung, 2008; } \\
\text { Limayem et } \\
\text { al., 2007) }\end{array}$ \\
\hline $\mathrm{CU}$ & $\begin{array}{l}\text { 1. How often did you use TaoBao for shopping during the last } 3 \text { weeks? } \\
\text { 2. Approximately how many times did you use TaoBao for shopping during the } \\
\text { last } 3 \text { weeks? }\end{array}$ & $\begin{array}{l}\text { (Limayem et } \\
\text { al., 2007) }\end{array}$ \\
\hline
\end{tabular}




\section{Data Analysis}

The Partial Least Squares (PLS) method was used to perform the statistical analysis in this study. PLS has enjoyed increasing popularity in recent years (Wold, 1989) because of its ability to model latent constructs under conditions of non-normality and in some small to medium-sized samples (Chin, 1998; Chin and Gopal, 1995; Compeau and Higgins, 1995).

\section{Results}

Following the two-step analytical procedures (Hair et al., 1998), we first examined the measurement model and then assessed the structural model.

\section{Measurement Model}

\section{Convergent Validity}

Convergent validity indicates the degree to which the items of an instrument that are theoretically related are also related in reality. Convergent validity was tested using three criteria of all constructs: (1) the composite reliability $(\mathrm{CR})$ should be at least 0.70 (Chin, 1998), (2) the average variance extracted (AVE) should be at least 0.50 (Fornell and Larcker, 1981), and (3) all item loadings should be greater than 0.707 (Chin, 1998). Table 3 presents the results of analysis. All our reflective measures fulfilled the recommended levels of composite reliability and average variance extracted. All item loadings were higher than the 0.71 benchmark.

\section{Table 3 - Descriptive Statistics and Psychometric Properties of Reflective Measures}

\begin{tabular}{|c|c|c|c|c|}
\hline Constructs & Item & Loading & Mean & S.D. \\
\hline \multirow{3}{*}{$\begin{array}{l}\text { Satisfaction } \\
(C R=0.93, A V E=0.82)\end{array}$} & SAT1 & 0.92 & 6.02 & 0.90 \\
\hline & SAT2 & 0.93 & 5.96 & 1.04 \\
\hline & SAT3 & 0.86 & 5.71 & 1.28 \\
\hline \multirow{3}{*}{$\begin{array}{l}\text { Perceived Enjoyment } \\
(\mathrm{CR}=0.93, \mathrm{AVE}=0.82)\end{array}$} & PEN1 & 0.90 & 5.95 & 1.13 \\
\hline & PEN2 & 0.92 & 5.68 & 1.06 \\
\hline & PEN3 & 0.91 & 5.74 & 1.16 \\
\hline \multirow{3}{*}{$\begin{array}{l}\text { Alternative Attractiveness } \\
(\mathrm{CR}=0.93, \mathrm{AVE}=0.81)\end{array}$} & AAT1 & 0.82 & 5.12 & 1.41 \\
\hline & AAT2 & 0.94 & 4.50 & 1.45 \\
\hline & AAT3 & 0.93 & 4.52 & 1.50 \\
\hline \multirow{2}{*}{$\begin{array}{l}\text { Continuance Intention } \\
(\mathrm{CR}=0.95, \mathrm{AVE}=0.91)\end{array}$} & ICU1 & 0.96 & 6.55 & 0.83 \\
\hline & ICU2 & 0.95 & 6.52 & 0.85 \\
\hline \multirow{3}{*}{$\begin{array}{l}\text { Habit } \\
(\mathrm{CR}=0.95, \mathrm{AVE}=0.87)\end{array}$} & HAB1 & 0.95 & 6.26 & 1.03 \\
\hline & HAB2 & 0.95 & 6.31 & 0.98 \\
\hline & HAB3 & 0.89 & 6.20 & 1.05 \\
\hline \multirow{2}{*}{$\begin{array}{l}\text { Continue to Use } \\
(\mathrm{CR}=0.91, \mathrm{AVE}=0.84)\end{array}$} & CU1 & 0.94 & 2.51 & 0.80 \\
\hline & CU2 & 0.89 & 6.26 & 4.55 \\
\hline
\end{tabular}

\section{Discriminant Validity}

Discriminant validity is indicated by low correlations between the measure of interest and the measure of other constructs (Fornell and Larcker, 1981). This validity can be assessed by having the square root of the average variance extracted (AVE) of each construct greater than the correlations between it and all other constructs. As shown in Table 4, the square root of the AVE of each construct is located on the diagonal of the table and is in bold.

\section{Structural Model}

Figure 3 presents the results of a longitudinal analysis with explanatory powers $\left(R^{2}\right)$, estimated path coefficients (significant paths indicated with an asterisk), and associated $t$-value of the paths. Tests of significance of all paths were performed using the bootstrap resampling procedure. The results show that the exogenous variables explain $22 \%$ of the variance in IS continuance, $63 \%$ of the variance in continuance intention, and $41 \%$ of the 
How the Conscious and Automatic Information Processing Modes Influence / Cheung et al.

variance in satisfaction. All hypothesized paths in the research model were found to be statistically significant (except the moderating effect of habit on the path from perceived enjoyment to continuance intention). Both continuance intention and habit exhibited strong and significant effects on IS continuance, with path coefficient of
0.23 and 0.26 respectively. Continuance intention in turn was significantly determined by satisfaction $(\beta=0.20, p<0.001)$, perceived enjoyment $\quad(\beta=0.17, \quad p<0.001)$, and alternative attractiveness $(-0.06, p<0.05)$. Perceived enjoyment also exhibited a strong effect on satisfaction $(\beta=0.65, p<0.01)$.

\section{Table 4 - Correlations Between Constructs with Reflective Measures (Diagonal Elements Are Square Roots of the Average Variance Extracted)}

\begin{tabular}{|l|c|c|c|c|c|c|}
\hline & AAT & HAB & PEN & CU & ICU & SAT \\
\hline Alternative Attractiveness (AAT) & $\mathbf{0 . 9 0}$ & & & & & \\
\hline Habit (HAB) & -0.16 & $\mathbf{0 . 9 3}$ & & & & \\
\hline Perceived Enjoyment (PEN) & -0.23 & 0.74 & $\mathbf{0 . 9 1}$ & & & \\
\hline Continue to Use (CU) & -0.13 & 0.43 & 0.42 & $\mathbf{0 . 9 2}$ & & \\
\hline Continuance Intention (ICU) & -0.19 & 0.73 & 0.68 & 0.42 & $\mathbf{0 . 9 5}$ & \\
\hline Satisfaction (SAT) & -0.20 & 0.55 & 0.65 & 0.31 & 0.59 & $\mathbf{0 . 9 1}$ \\
\hline $\begin{array}{l}\text { AAT=alternative attractiveness; HAB=habit; PEN=perceived enjoyment; CU= continue to use; ICU= continuance } \\
\text { intention; SAT=satisfaction; }\end{array}$
\end{tabular}

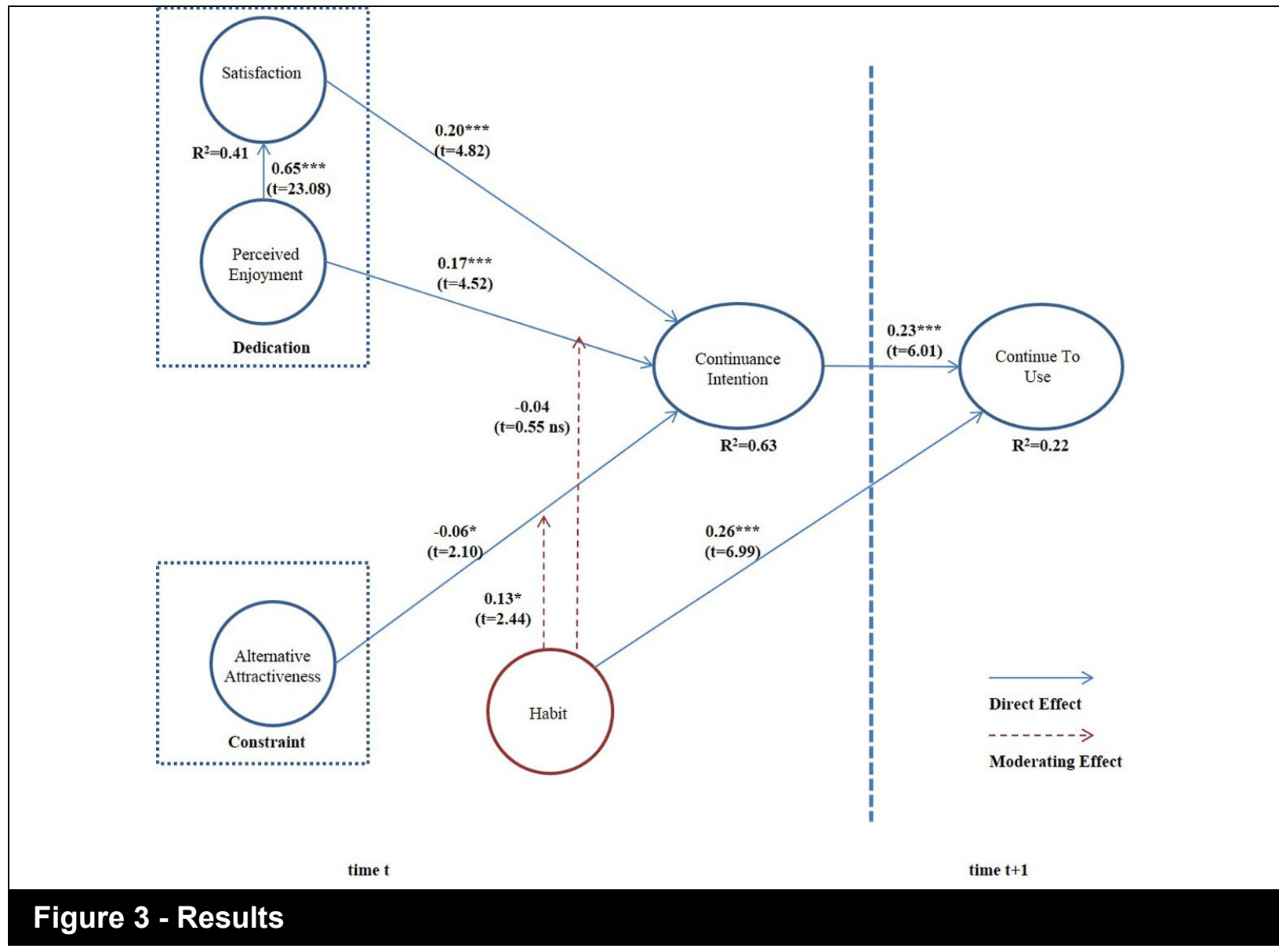


In testing for interaction effects using PLS, the hierarchical process was used to compare the $R^{2}$ value for the interaction model with that for the main effects model, which excluded the interaction construct. The difference in $\mathrm{R}^{2} \mathrm{~s}$ was used to assess the overall effect size $\mathrm{f}^{2}$ for the interaction where $0.02,0.15$, and 0.35 had been suggested as small, moderate, and large effects, respectively (Cohen, 1988). As indicated in Table 5 , the model in which habit was proposed to moderate the link between alternative attractiveness and continuance intention possessed a significantly higher explanatory power than the main effect model. Moreover, the effect size for the interaction was 0.07 (small effect).

\section{Table 5 - Hierarchical Test}

\begin{tabular}{|l|c|}
\hline & R2 \\
\hline Main effect model & 0.60 \\
\hline Interaction effect model & 0.63 \\
\hline f2 & 0.07 \\
\hline
\end{tabular}

Notes: f2 $=$ [R2 (interaction effect model) -R2 (main effect model)]/[1 -R2 (main effect model)]

Finally, the effects of control variables (including experience of e-commerce websites, age, gender and income) on the research variables were also examined. Only income was found to be significantly related to continue to use $(\beta=0.169, p<0.05)$. That is to say, continue to use were found to be greater among high income consumers than low income consumers.

\section{Discussion and Implication}

The objective of this study is to address a gap in our understanding of the operation and interplay of the conscious and automatic information processes in shaping consumers' continuance decision. Regarding the conscious information processing mode, the continued use is driven by two contrasting forces: dedication (satisfaction and perceived enjoyment) and constraint (alternative attractiveness). Regarding the automatic information processing mode, continued use is driven by habit and its interaction with key conscious elements (i.e., perceived enjoyment and attractiveness of alternative) in the decision process. Our model is empirically validated in a longitudinal setting.

\section{Discussion of Key Findings}

The two processing modes work in parallel to explain the continued use of an information system. The two contrasting forces (satisfaction, perceived enjoyment, and alternative attractiveness) have significant direct effects on continuance intention. Habit exhibits a significant moderating effect on the relationship between alternative attractiveness and continuance intention, but it does not have any significant moderating effect on the relationship between perceived enjoyment and continuance intention. This may be explained by the fact that habit activates the heuristic information processing mode and makes individuals less attentive to new information, and thus the impact of alternative attractiveness to the continuance intention diminishes (Polites and Karahanna, 2012). However, the habitual use of an information system does not intensify their perceptions toward the dedication of using the IS. This relationship may need further investigation.

\section{Theoretical Implications}

This study enriches existing literature on IS continuance by providing a theoretical understanding of the interplay of the conscious and automatic processes in shaping IS continuance. Particularly, the result illustrates that the two information processes operate in parallel to determine the continued use of an e-commerce website. In addition, we have clarified that 
How the Conscious and Automatic Information Processing Modes Influence / Cheung et al.

psychological processes range on a continuum from highly conscious to entirely unconscious, and the two processing modes interact at various stages of processing. For instance, habit activates the heuristic information processing mode and facilitates decision making through interacting with key elements of the rational decision process. Anecdotal evidence has suggested that perceptions, intentions, habits, and behaviors are highly related, but there has been little empirical evidence regarding this issue. In this study, we tested our research model and hypotheses in a longitudinal setting. We have better confidence in drawing cause-effect inferences on the relationship between the two processing modes and consumers' continuance decision.

\section{Practical Implications}

Studying how the operation and interplay of the conscious and automatic processes determine IS continuance has practical implications for organizations that wish to keep consumers to continue using their online platforms. In addition, the results may be particularly useful for websites/emarketplaces that aim at retaining their consumers. Our results show that both conscious and automatic information processing modes play a role in explaining their continuance. In addition, once habit of using an e-commerce website is formed, it is very likely that consumers will pay less attention to the alternatives. Website administrators should develop strategies that encourage consumers to form habit of visiting their sites. For instance, they can provide incentives (bonus points) for their every visit in their websites (especially for the new consumers). They can also continue to improve their websites so that their consumers are satisfied with usage experience.

\section{Limitations of the Study and Future Research Directions}

In interpreting the results of this study, one must pay attention to a number of limitations. First, the research model was tested in a particular context, e-commerce websites. As online shopping has become one of the most popular online activities, we believe that habit can be easily formed and exerts a strong effect on subsequent use. Thus, the context is relevant and suitable for the current investigation. However, the domain of e-commerce websites may differ from other contexts. Care must be taken when extrapolating the findings to other types of information systems. To keep the model parsimonious, the proposed model only considers perceived enjoyment as the perceived values in the research model. Perceived enjoyment is believed to be closely relevant to the context of online shopping. There are a number of beliefs, such as perceived usefulness, perceived ease of use, perceived playfulness, and the like, that researchers may want to continue to explore their roles in the evaluation process and their impact on continuance intention. Finally, it is possible that this study omits some important factors that drive IS continuance. For example, we mainly focus on the interplay of the two processing modes and explore their relationships with consumers' continuance decision. This study only included the cognitive affect (i.e., satisfaction) to explain IS continuance. Future studies may continue to explore the operation of other forms of affect as well as how they interact with the two processing modes (conscious and automatic processes) to determine consumers' continuance decision.

\section{Acknowledgements}

The authors acknowledge with gratitude the generous support of the Hong Kong Baptist University for the Faculty Research Grant (FRG) FRG2/14-15/018 without which the timely production of the current publication would not have been feasible. Xiabing Zheng is the corresponding author. 


\section{References}

Aarts, $H_{\text {., }}$ Paulussen, T., and Schaalma, $H$. (1997). "Physical Exercise Habit: On the Conceptualization and Formation of Habitual Health Behaviours," Health Education Research, 12(3), pp. 363-374.

Agarwal, R., and Karahanna, E. (2000). "Time Flies When You're Having Fun: Cognitive Absorption and Beliefs About Information Technology Usage," MIS Quarterly, 24(4), pp. 665-694.

Bargh, J.A., and Chartrand, T.L. (1999). "The Unbearable Automaticity of Being," American Psychologist, 54(7), pp. 462-479.

Bem, D.J. (1972). Self-Perception Theory. San Diego, CA: Academic Press.

Bendapudi, N., and Berry, L.L. (1997). "Customers' Motivations for Maintaining Relationships with Service Providers," Journal of Retailing, 73(1), pp. 15-37.

Bhattacherjee, A. (2001). "Understanding Information Systems Continuance: An Expectation-Confirmation Model," MIS Quarterly, 25(3), pp. 351-370.

Blau, P.M. (1964). Exchange and Power in Social Life. Transaction Publishers.

Burton-Jones, A., and Gallivan, M.J. (2007). "Toward a Deeper Understanding of System Usage in Organizations: A Multilevel Perspective," MIS Quarterly, 31(4), pp. 657-679.

Chartrand, T.L., and Fitzsimons, G.J. (2011). "Nonconscious Consumer Psychology," Journal of Consumer Psychology, 21(1), pp. 1-3.
Cheung, C.M.K., and Lee, M.K.O. (2009). "Understanding the Sustainability of a Virtual Community: Model Development and Empirical Test," Journal of Information Science, 35(3), pp. 279-298.

Cheung, C.M.K., Lee, M.K.O., and Lee, Z.W.Y. (2013). "Understanding the Continuance Intention of Knowledge Sharing in Online Communities of Practice through the PostKnowledge-Sharing Evaluation Processes," Journal of the American Society for Information Science and Technology, 64(7), pp. 1357-1374.

Chin, W.W. (1998). "The Partial Least Squares Approach to Structural Equation Modeling," in Modern Methods for Business Research. Mahwah, NJ: G. A. Marcoulides (ed.) Lawrence Erlbaum Associates.

Chin, W.W., and Gopal, A. (1995). "Adoption Intention in Gss: Relative Importance of Beliefs," SIGMIS Database, 26(2-3), pp. 42-64.

Chiu, C.M., and Wang, E.T.G. (2008). "Understanding Web-Based Learning Continuance Intention: The Role of Subjective Task Value," Information \& Management, 45(3), pp. 194-201.

Cohen, J. (1988). Statistical Power Analysis for the Behavioral Sciences. Hillsdale, NJ: 2nd ed. Lawrence Erlbaum Associates.

Colgate, M., and Lang, B. (2001). "Switching Barriers in Consumer Markets: An Investigation of the Financial Services Industry," Journal of Consumer Marketing, 18(4), pp. 332-347.

Compeau, D.R., and Higgins, C.A. (1995). "Application of Social Cognitive 
How the Conscious and Automatic Information Processing Modes Influence / Cheung et al.

Theory to Training for Computer Skills," Information Systems Research, 6(2), pp. 118-143.

DeLone, W.H., and McLean, E.R. (2003). "The Delone and Mclean Model of Information Systems Success: A Ten-Year Update," Journal of Management Information Systems, 19(4), pp. 9-30.

Fornell, C., and Larcker, D.F. (1981). "Evaluating Structural Equation Models with Unobservable Variables and Measurement Error," Journal of Marketing Research, 18(1), pp. 3950.

Gefen, D. (2003). "Tam or Just Plain Habit: A Look at Experienced Online Shoppers," Journal of Organizational and End User Computing, 15(3), pp. $1-13$.

Hair, J.F., Black, W.C., Babin, B.J., Anderson, R.E., and Tatham, R.L. (1998). Multivariate Data Analysis. Upper Saddle River, NJ: 5th Ed., Prentice Hall,.

Hsieh, J.J.P.-A., Rai, A., and Keil, M. (2008). "Understanding Digital Inequality: Comparing Continued Use Behavioral Models of the SocioEconomically Advantaged and Disadvantaged," MIS Quarterly, 32(1), pp. 97-126.

Jasperson, J., Carter, P.E., and Zmud, R.W. (2005). "A Comprehensive Conceptualization of Post-Adoptive Behaviors Associated with Information Technology Enabled Work Systems," MIS Quarterly, 29(3), pp. 525-557.

Jing, X., and Xie, J. (2011). "Group Buying: A New Mechanism for Selling through Social Interactions,"
Management science, 57(8), pp. 1354-1372.

Karahanna, E., Straub, D.W., and Chervany, N.L. (1999). "Information Technology Adoption across Time: A CrossSectional Comparison of PreAdoption and Post-Adoption Beliefs," MIS Quarterly, 23(2), pp. 183-213.

Keaveney, S.M. (1995). "Customer Switching Behavior in Service Industries: An Exploratory Study," Journal of Marketing, 59(2), p. 71.

Kim, B. (2010). "An Empirical Investigation of Mobile Data Service Continuance: Incorporating the Theory of Planned Behavior into the ExpectationConfirmation Model," Expert Systems with Applications, 37(10), pp. 7033-7039.

Kim, S.S., Malhotra, N.K., and Narasimhan, S. (2005). "Two Competing Perspectives on Automatic Use: A Theoretical and Empirical Comparison," Information Systems Research, 16(4), pp. 418-432.

Kim, S.S., and Son, J.-Y. (2009). "Out of Dedication or Constraint? A Dual Model of Post-Adoption Phenomena and Its Empirical Test in the Context of Online Services.," MIS Quarterly, 33(1), pp. 49-70.

Liang, H., Saraf, N., Hu, Q., and Xue, Y. (2007). "Assimilation of Enterprise Systems: The Effect of Institutional Pressures and the Mediating Role of Top Management," MIS Quarterly, 31(1), pp. 59-87.

Limayem, M., and Cheung, C.M.K. (2008). "Understanding Information Systems Continuance: The Case of InternetBased Learning Technologies," 
Information \& Management, 45(4), pp. 227-232.

Limayem, M., and Hirt, S.G. (2003). "Force of Habit and Information Systems Usage: Theory and Initial Validation," Journal of the Association for Information Systems, 4), pp. 65-95.

Limayem, M., Hirt, S.G., and Cheung, C.M.K. (2007). "How Habit Limits the Predictive Power of Intention: The Case of Information Systems Continuance," MIS Quarterly, 31(4), pp. 705-737.

Ortiz de Guinea, A., and Markus, M.L. (2009). "Why Break the Habit of a Lifetime? Rethinking the Roles of Intention, Habit, and Emotion in Continuing Information Technology Use," MIS Quarterly, 33(3), pp. 433444.

Pavlou, P.A., Huigang, L., and Yajiong, X. (2007). "Understanding and Mitigating Uncertainty in Online Exchange Relationships: A Principal-Agent Perspective," MIS Quarterly, 31(1), pp. 105-136.

Ping Jr, R.A. (1993). "The Effects of Satisfaction and Structural Constraints on Retailer Exiting, Voice, Loyalty, Opportunism, and Neglect," Journal of Retailing, 69(3), pp. 320-352.

Podsakoff, P.M., MacKenzie, S.B., Lee, J.Y., and Podsakoff, N.P. (2003). "Common Method Biases in Behavioral Research: A Critical Review of the Literature and Recommended Remedies," Journal of Applied Psychology, 88(5), p. 879.

Polites, G.L., and Karahanna, E. (2012). "Shackled to the Status Quo: The Inhibiting Effects of Incumbent
System Habit, Switching Costs, and Inertia on New System Acceptance," MIS Quarterly 36(1), pp. 21-42.

Rai, A., Lang, S.S., and Welker, R.B. (2002). "Assessing the Validity of Is Success Models: An Empirical Test and Theoretical Analysis," Information Systems Research, 13(1), pp. 50-69.

Seiders, K., Voss, G.B., Grewal, D., and Godfrey, A.L. (2005). "Do Satisfied Customers Buy More? Examining Moderating Influences in a Retailing Context," Journal of Marketing, 69(4), pp. 26-43.

Thong, J.Y.L., Hong, S.-J., and Tam, K.Y. (2006). "The Effects of PostAdoption Beliefs on the ExpectationConfirmation Model for Information Technology Continuance," International Journal of HumanComputer Studies, 64(9), pp. 799810.

Venkatesh, V., and Brown, S.A. (2001). "A Longitudinal Investigation of Personal Computers in Homes: Adoption Determinants and Emerging Challenges," MIS Quarterly, 25(1), pp. 71-102.

Venkatesh, V., and Davis, F.D. (2000). "A Theoretical Extension of the Technology Acceptance Model: Four Longitudinal Field Studies," Management Science, 46(2), p. 186.

Verhoef, P.C. (2003). "Understanding the Effect of Customer Relationship Management Efforts on Customer Retention and Customer Share Development," Journal of Marketing, 67(4), pp. 30-45.

Verplanken, B., and Aarts, H. (1999). "Habit, Attitude, and Planned Behaviour: Is Habit an Empty Construct or an Interesting Case of Goal-Directed 
How the Conscious and Automatic Information Processing Modes Influence / Cheung et al.

Automaticity?," European Review of Social Psychology, 10(1), pp. 101134.

Wold, H. (1989). "Introduction to the Second Generation of Multivariate Analysis," in Theoretical Empiricism. New York: Paragon House, pp. vii-xi.

Wood, W., and Neal, D.T. (2009). "The Habitual Consumer," Journal of Consumer Psychology, 19(4), pp. 579-592.

Ye, C., and Potter, R. (2011). "The Role of Habit in Post-Adoption Switching of Personal Information Technologies: An Empirical Investigation," Communications of the Association for Information Systems, 28(1), p. Article 35.

Zhang, K.Z.K., Lee, M.K.O., Cheung, C.M.K., and Chen, H. (2009). "Understanding the Role of Gender in Bloggers' Switching Behavior," Decision Support Systems, 47(4), pp. 540-546.

Zhang, P. (2013). "The Affective Response Model: A Theoretical Framework of Affective Concepts and Their Relationships in the lct Context," MIS Quarterly, 37(1).

\section{About the Authors}

Christy M. K. Cheung is an Associate Professor at Hong Kong Baptist University.
She received her Ph.D. from City University of Hong Kong. Her research interests include virtual community, knowledge management, social computing technology, and IT adoption and usage. Her research articles have been published in MIS Quarterly, Decision Support Systems, Information \& Management, Journal of the American Society for Information Science and Technology, and Information Systems Frontiers.

Xiabing Zheng is currently a Postdoctoal Fellow in School of Manangement, University of Science and Technology of China. She received the B.Sc. degree in Statistics and the Ph.D. degree in Management Science from University of Science and Technology of China, and a joint Ph.D. degree in Information Systems from City University of Hong Kong. Her research interests mainly focus on electronic commerce and knowledge management in new digital social media.

Matthew K. O. Lee is a Chair Professor of Information Systems \& E-Commerce at the College of Business, City University of Hong Kong. He holds a Ph.D. degree from the University of Manchester (UK). He has a research and professional interest in IT based innovation adoption and diffusion, knowledge management, social computing, electronic commerce, and legal informatics. His publications in the information systems and electronic commerce areas include a book as well as over one hundred referred articles in international journals, conference proceedings, and research textbooks. He has published in top journals in his field and his work has received numerous citations. 